\title{
In vivo Pharmacological Investigation of Leaf of Polygonum hydropiper (L.)
}

\section{Rumana Akhter, Md. Aminul Haque, Mohiuddin Ahmed Bhuiyan and Mohammad Shahriar}

Phytochemistry Research Laboratory, Department of Pharmacy, University of Asia Pacific, Dhaka, Bangladesh

\begin{abstract}
The present study was planned to evaluate the anti-nociceptive, gastro intestinal motility, anti-pyretic and acute toxicity studies of leaf extract of Polygonum hydropiper leaves in albino mice following oral administration. The results showed that the anti-nociceptive activity in the scale of ethanol $>n$-hexane $>$ petroleum ether $>$ chloroform $>$ methanol extract showed a significant result compared to diclofenac sodium. Chloroform extract showed significant results on gastro intestinal motility test. Ethanol \& chloroform extracts showed considerable reduction of temperature at higher doses within 1st hour on yeast induced pyrexia in albino mice. Highest dose introduced as $1000,2000 \& 4000 \mathrm{mg} / \mathrm{kg}$ body weight of each extracts in acute toxicity test did not shown any sign of toxicity in albino mice in one week observation.
\end{abstract}

Key words: Polygonum hydropiper, anti-nociceptive activity, gastro intestinal motility, anti-pyretic activity and acute toxicity.

\section{INTRODUCTION}

Plants that possess therapeutic properties or exert beneficial pharmacological effects on the human body are generally designated as medicinal plants. These plants naturally synthesize and accumulate some secondary metabolites, like alkaloids, sterols, terpens, flavanoids, saponins, glycosides cyanogenics, tannins, resins, quinines, volatile oils, etc. The medicinal plants have been used for treatment of illness and diseases, since the dawn of time. Ancient Chinese scriptures and Egyptian papyrus hieroglyphics describe medicinal uses for plants. Indigenous cultures (e.g. African and native American) used herbs in their healing rituals, while others developed traditional medicinal systems (e.g. Ayurvedic and traditional Chinese medicine) in which herbal therapies were used. Researchers have found that people in different parts of the world tend to use the same or similar for the treating of same illness.

Correspondence to: Mohammad Shahriar

Mobile: +88-011-99-844-259

E-mail: shahriar@uap-bd.edu

Dhaka Univ. J. Pharm. Sci. 12(2): 165-169, 2013 (December)
Recently World Health Organization (WHO) estimated that $80 \%$ of people worldwide rely on herbal medicines partially for their primary health care. It has been recorded that about 450 to 500 plants growing or available in Bangladesh have therapeutic values. ${ }^{1,2}$ In Bangladesh, people living in the remote hilly areas, such as, ethnic communities rely mostly on herbal medicines. Bangladesh, a country fertile deltaic land has a rich diversity of flora of medicinal plants scattered throughout the forests, crop fields, roadsides gardens and wastelands.

Polygonum hydropiper L. is an important medicinal plant belongs to the family of Polygonaceae. The whole plant has been found to contain flavones and flavanoid glycosides, such as quercetin galactosides, a sesquiterpene acid, viscosumic acid, oxymethyl-anthraquinones and polygonic acid. $^{3}$ The plant has some insecticidal properties $^{4,5}$ and also possesses bitter, stimulant, tonic, diuretic, carminative, anthelmintic, emmeragogue, haemostatic and lithotripter properties. ${ }^{6}$ The whole plant, either on its own or 
mixed with other herbs, is used in the treatment of a wide range of ailments including diarrhea, dyspepsia, itching skin, excessive menstrual bleeding and hemorrhoids. ${ }^{7}$ This species is of economic interest due to its wide range of pharmacological activities and one of the major constraints in utilizing natural populations is the existence of plant to plant chemo variability. That is why; there is an increasing awareness in people for the use of this herbal medicinal plant day by day.

\section{MATERIAL AND METHODS}

Plant collection. Whole plant sample of Polygonum hydropiper was collected from Tongi, Gazipur, Dhaka, Bangladesh in June 2012. Then it was submitted to the Bangladesh National Herbarium, Mirpur, Dhaka for its identification (Accession No. 37756).

Plant material preparation. Whole plant sample was separated in different parts and sun dried for 7 days. Then leaves were taken and oven dried for 3 hours at $40^{\circ} \mathrm{C}$ temperature. Then $800 \mathrm{gm}$ dried leaves were ground to a coarse powder using high capacity grinding machine. About $715 \mathrm{gm}$ of powders were sieved to get fine powder. Finally $630 \mathrm{gm}$ of powder was obtained which was then stored in air tight container with necessary marking for identification and kept in cool, dark and dry place for further investigation. According to Patil et al. ${ }^{8}$ the whole plant material was extracted with methanol, ethanol, chloroform, petroleum ether and n-hexane using soxhlet extraction apparatus for six to seven hours at a temperature not exceeding the boiling point of the solvent used. The extracts were named as ME, EE, Ch-E, Pt-E, n-HE, respectively.

Animals for in vivo pharmacological investigation. For the experiment Swiss albino mice of either sex, 4-5 weeks of age, weighing between 10-24 gm were collected from ICDDR,B, Dhaka. Animals were maintained under standard environmental conditions (temperature: (27.0 \pm $1.0)^{\circ} \mathrm{C}$, relative humidity: $(55-65) \%$ and 12 hour light/12 hour dark cycle) and free access to feed and water. The animals were acclimatized to laboratory condition for one week prior to experiments. All protocols for animal experiment were approved by the institutional animal ethical committee.

Tail immersion test. The tail immersion method was used to evaluate the central mechanism of analgesic activity. Here, the painful reactions in animals were produced by thermal stimuli by dipping the tip of the tail in hot water. ${ }^{9}$ On the test day, Swiss Albino mice were divided into twelve groups of six mice each. Here, diclofenac - $\mathrm{Na}(50 \mathrm{mg} / \mathrm{kg})$ was used as standard drug. Animals were fasted for 16 hours with free access to water. After administration of standard and test drugs, the basal reaction time was measured by immersing the tail tips of mice (last 1-2 cm) in hot water bath, where temperature was previously adjusted at $51^{\circ} \mathrm{C}$. The actual flick response of mice that is time taken in second to withdraw it from hot water source was calculated and result were compared with control group. The latent period of the tail-flick response was determined at $0,30,60,90$ and 120 minute after the administration of drugs.

Gastro intestinal activity. Forty eight Swiss Albino mice, weighing between 10-20 g were selected and housed properly for 10 days before performing the experiment. On the test day, the animals were divided into eight groups of six mice each. They were weighed and deprived of food, with free access to water. Three hours after food deprivation, the animals in group 1 received orally by gavages $5 \mathrm{ml} / \mathrm{kg}$ body weight of $0.9 \% \mathrm{NaCl}$ (normal saline) as control group, while those in group 2 received $50 \mathrm{mg} / \mathrm{kg}$ body weight of loperamide as standard group. The other six groups received their respective doses as shown in the table. After $90 \mathrm{~min}$, $0.3 \mathrm{ml}$ of an aqueous suspension of $5 \%$ charcoal in normal saline was administered to each animal orally by gavages (time $90 \mathrm{~min}$ ). Sixty minutes later they had free access to food (time $150 \mathrm{~min}$ ). The animals were observed at $5 \mathrm{~min}$ intervals until feces with 
charcoal were eliminated (maximum time of observation was $300 \mathrm{~min}$ ). Charcoal was observed on the feces using normal light when it was easily visible, or using a microscope to help the identification of the black spots. The results were based on the time for the charcoal to be eliminated. ${ }^{10}$

Anti-pyretic activity. Fifty six Albino Swiss mice of both sexes (10-20 gm) were randomly divided into 8 groups and fasted overnight before the experiment with free access to water. The normal body temperature of each mouse was measured rectally at predetermined intervals and recorded. Fever was induced according to the method described by Smith and Hambourger (1935). ${ }^{11}$ A lubricated thermometer probe was inserted 3-4 $\mathrm{cm}$ deep into the rectum and fastened to the tail by adhesive tape. Temperature was measured on digital thermometer. After measuring the basal rectal temperature, animals were injected subcutaneously with $10 \mathrm{ml} / \mathrm{kg}$ of $20 \%$ w/v brewer's yeast in NSS in the dorsum of the mice. Mice were then returned to their housing cages. Eighteen hours after brewer's yeast injection, the animals were again restrained for rectal temperature recording, as described previously. Only mice that showed an increase in temperature of at least $1{ }^{0} \mathrm{C}$ were used for this study. The extracts at the doses of $200 \& 400 \mathrm{mg} / \mathrm{kg}$ body weight were administered orally to four groups of animals. The control group received $1 \mathrm{ml} / \mathrm{kg}$ body weight dose of vehicle $(0.9 \%$ $\mathrm{NaCl}$ solution) and the standard group received paracetamol (50 mg/kg body weight) orally. Rectal temperature was measured at $1 \mathrm{hr}$ intervals for $4 \mathrm{hr}$ after the extract/drug administration. The rectal temperature of normal rats (normothermic) was also measured at $1 \mathrm{hr}$. intervals for $7 \mathrm{hr} .{ }^{12}$ The results are expressed as percentage of the pre-drug temperature recorded for the same animals using the formula of Makonnan et al. (2003). ${ }^{13}$

$$
\% \text { reduction }=\frac{\text { Yeast induced pyrexia }- \text { Post treatment temperature }}{\text { Yeast induced pyrexia }} \times 100 \%
$$

Acute toxicity Acute toxicity describes the effects of a substance which result either from a single exposure or from multiple exposures in a short space of time (usually less than 24 hours). The acute toxicity study was conducted to find out $\mathrm{LC}_{50}$ of the test samples. The test samples were administered orally to the test animals at different concentration (1000, $2000 \& 4000 \mathrm{mg} / \mathrm{kg}$ body weight). After administration of the extract solutions mortality or sign of any toxicity was observed for one hour. Then the test animals were observed every 1 hour for next 5-6 hours. The animals were kept under observation for 1 week. ${ }^{14-18}$

\section{RESULTS AND DISCUSSION}

Anti-nociceptive activity (tail immersion test) Tail immersion method, the heat itself acts as a source of pain. The different concentrations of chloroform and petroleum ether extracts of plant (200 and $400 \mathrm{mg} / \mathrm{kg}$ ) and diclofenac $\mathrm{Na}(50 \mathrm{mg} / \mathrm{kg})$ were administered to mice and observed the basal reaction time in different time intervals. The basal reaction time increased with increasing the concentrations along with increasing the time. The basal reaction time was more for standard drug when compared to plant extracts. In case of plant extracts the ethanol extracts shows more reaction time and that is recovered after $120 \mathrm{~min}$ the order of potency in 60 min after dose administration is diclofenac $\mathrm{Na}>$ ethanol $>$ n-Hexane $>$ petroleum ether $>$ chloroform $>$ methanol $>$ normal saline ( Figure 1).

Gastro intestinal motility test. The time spent in eliminating the charcoal plug showed in table 1 . Comparisons indicate chloroform extract of leaf of $P$. hydropiper shows very close charcoal elimination time like standard loperamide.

Anti-pyretic tests. From Figure 2, in anti-pyretic test methanol extract at dose $400 \mathrm{mg} / \mathrm{kg}$ body weight, ethanol extract at $200 \& 400 \mathrm{mg} / \mathrm{kg}$ body weight and chloroform extract at $200 \& 400 \mathrm{mg} / \mathrm{kg}$ body weight dose has shown quite satisfactory results compared to standard drug paracetamol $50 \mathrm{mg} / \mathrm{kg}$ body weight. 
The percent reduction of temperature with leaf extract of P. hydropiper has been shown in Figure 3.

Acute toxicity test. In the time of investigation of acute toxicity none of the extracts ranging from
$1000,2000,4000 \mathrm{mg} / \mathrm{kg}$ body weight showed any sign of toxicity in the period of one week.

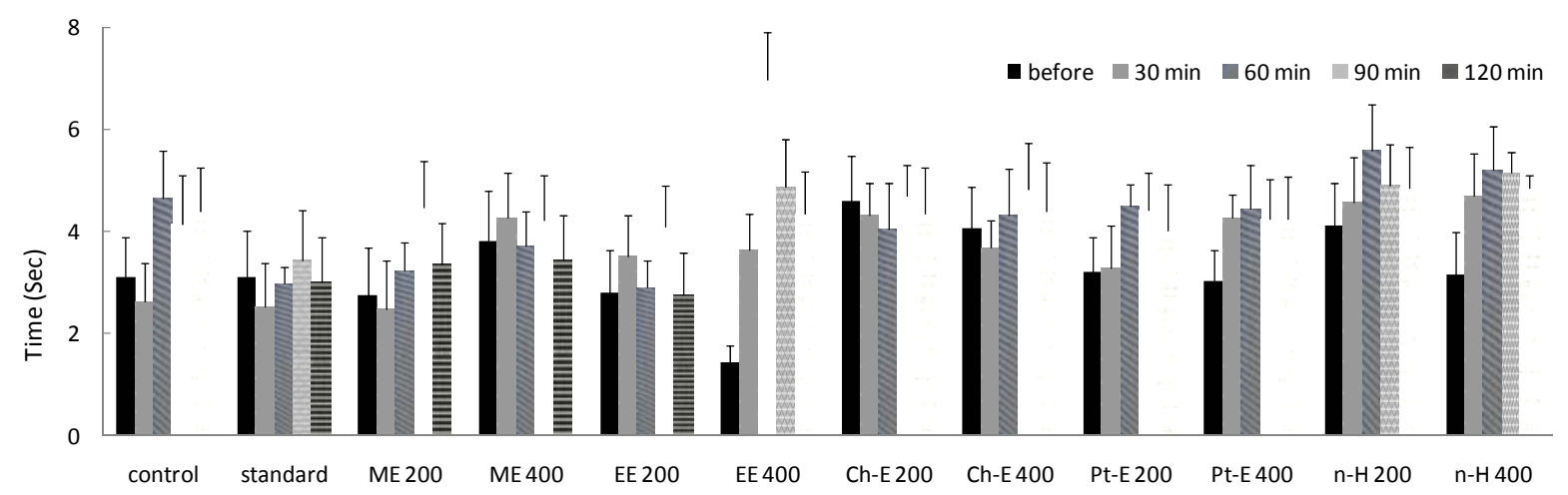

Figure 1. Results of tail immersion test after administration of doses of control, standard and extracts. Data represent the mean \pm S.D. $(n=6)$

Table 1. Gastro-intestinal motility investigation through charcoal defecation time (min)

\begin{tabular}{lcc}
\hline Group & Dose $(\mathrm{mg} / \mathrm{kg})$ body weight & Charcoal defecation time $(\mathrm{min})$ \\
\hline Control & $5 \mathrm{ml} / \mathrm{kg}$ & $125.2 \pm 3.96$ \\
Standard & 50 & $189.8 \pm 7.92$ \\
& 250 & $126.6 \pm 2.96$ \\
ME & 500 & $131.8 \pm 4.66$ \\
& 250 & $134.2 \pm 6.46$ \\
EE & 500 & $132.8 \pm 5.02$ \\
& 250 & $170.2 \pm 7.36$ \\
Ch-E & 500 & $171.8 \pm 7.22$ \\
\hline
\end{tabular}

Values are expressed as mean \pm S.D. $(n=6)$

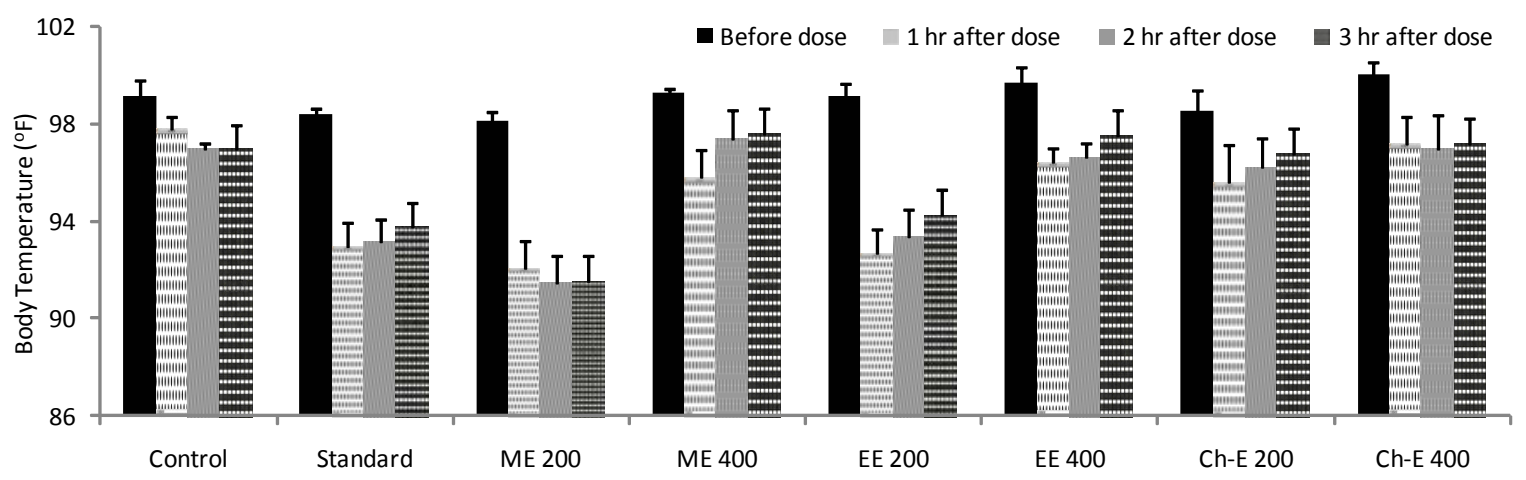

Figure 2. Anti pyretic activity after administration of doses of control, standard and extracts. Data represent the mean \pm S.D. $(n=6)$ 


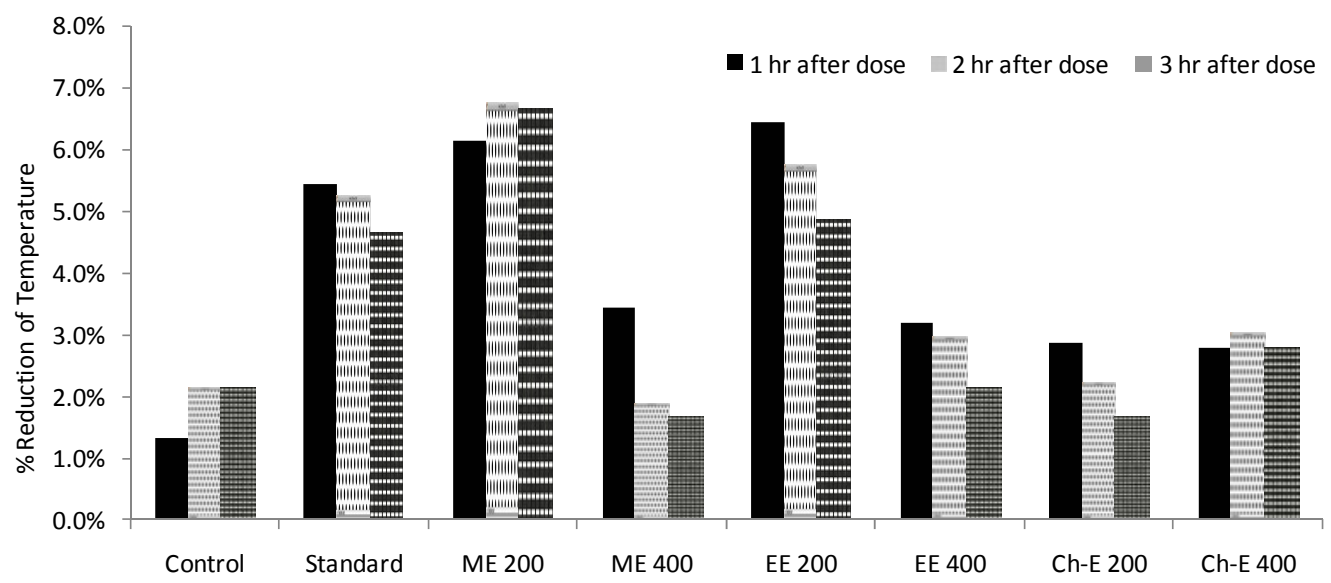

Figure 3. Percent reduction of temperature after administration of doses of control, standard and extracts

\section{CONCLUSION}

Due to wide range of pharmacological activities of Polygonum hydropiper, it has been used traditionally for a long time. Results of the present study made the statement about the plant justified. Further phytochemical studies can be done for isolation of pure compounds responsible for the specific pharmacological action of this study.

\section{REFERENCES}

1. Yusuf, M., Chowdhury, J.U., Wahab, M. A. and Begum, J. 1994. Medicinal Plants of Bangladesh. Bangladesh Council of Scientific and Industrial Research.

2. Ghani, A. 1998. Medicinal Plants of Bangladesh: Chemical Constituents \& Uses. Asiatic Society of Bangladesh, 460.

3. Furukawa, T., Eshima, A., Kouya, M., Takio, S. and Takano, H. 2002. Coordinate expression of genes involved in catchin biosynthesis in Polygonum hydropiper cells. Plant Cell Reports. 21, 385-389.

4. Mollah, J.U. and Islam, W. 2005. Effect of Polygonum hydropiper L. extracts on the oviposition and egg viability of Callosobruclues cinensis F. (Coleoptera: Bruchidae). J. Bioscience 12, 101-109.

5. Kundu, B.R., Ara, R., Begum, M.M. and Sarkar, Z.I. 2007. Effect of Bishkatali, Polygonum hydropiper L. plant extracts against the red flour beetle, Tribolium castaneum Herbst. Univ. J. Zool. 26, 93-97.

6. Sharma, R. 2003. Medicinal plants of India-An encyclopedia. In Daya Publishing House. 46-47.

7. Chevallier, A. 1996. The Encyclopedia of Medicinal Plants. In Dorling Kindersley. London. 185.
8. Patil, S.D., Ahale, S.V. and Surana, S.J. 2010. Antiashmatic Antialargic Activity of Balantis aegyptiaka (Delile) Balanitaceae. Pharmacologyonline. 2, 487-495.

9. Luiz, C.D.S., Mirtes, C., Sigrid, L.J., Mizuekirizawa, M., Cecilia, G. and Jrotin, G. 1988. J. Ethno Pharmacol. . 24, 205-211.

10. Marona, H.R.N., and Lucchesi, M. B. B. 2004. Protocol to refine intestinal motility test in mice. Laboratory Animals. 38, 257-260.

11. Smith, P.K. and Hambourger, W.E. 1935. The ratio of the toxicity of acetanilamide to its antipyretic activity in rats. $J$. Pharm. Exp. Therapeutics. 54, 346.

12. Chomchuen, S., Singharachai, C., Ruangrungsi, N. and Towiwat, P. 2010. Anti Pyretic Effect of The Ethanolic Extract Of Ficus Racmosa Root In Rats. J. Health Res. 24, 23-28.

13. Makonnen, E., Debella, A., Zerihun, L., Abebe, D. and Teka, F. 2003. Antipyretic properties of the aqueous and ethanol extracts of the leaves of Ocimum suave and Ocimum lamiifolium in mice. J. Ethno Pharmacol. 88, 85-91.

14. OECD. Guidance Document on Acute Oral Toxicity Testing. Environmental Health and Safety Monograph Series on Testing and Assessment N.24. Paris; 2001.

15. OECD. OECD Guidelines for Acute Toxicity of Chemicals. Organization for Economic Co-operation and Development. No. 420. Paris; 2001.

16. OECD. OECD Guidelines for Acute Toxicity of Chemicals. Organization for Economic Co-operation and Development. No. 423. Paris; 2001.

17. OECD. OECD Guidelines for Acute Toxicity of Chemicals. Organization for Economic Co-operation and Development. No. 425. Paris: France; 2001.

18. Walum, E. 1998. Acute oral toxicity Environ. Health Prospect. 106, 497-503. 